\title{
CATALYST trial protocol: A multicentre, open-label, phase II, multi-arm trial for an early and accelerated evaluation of the potential treatments for COVID-19 in hospitalised adults
}

Tonny Veenith ${ }^{1,2 *}$, Benjamin A. Fisher ${ }^{3,4,5 *}$, Daniel Slade ${ }^{5}$, Anna Rowe ${ }^{4,5}$, Rowena Sharpe ${ }^{5}$, David R. Thickett $^{2,6}$, Tony Whitehouse ${ }^{1,2}$, Matthew Rowland ${ }^{7}$, James Scriven ${ }^{8}$, Dhruv Parekh ${ }^{1,2,6}$, Sarah J. Bowden ${ }^{5}$, Joshua S. Savage ${ }^{5}$, Duncan Richards ${ }^{9}$, Julian Bion ${ }^{1}+$, Pamela Kearns $s^{4,5}+$, Simon Gates ${ }^{5}+$, on behalf of CATALYST investigators ${ }^{\&}$

* These authors have made an equal contribution.

+ These authors have made an equal contribution.

\& Additional investigators of the CATALYST Trial are listed in Supplemental Appendix 1.

* Corresponding authors contact details:

Prof. Tonny Veenith, Institute of Inflammation and Ageing, College of Medical and Dental Sciences, University of Birmingham, Birmingham, B15 2TT, UK. Email: t.v.veenith@bham.ac.uk or;

Dr Benjamin A. Fisher, Institute of Inflammation and Ageing, College of Medical and Dental Sciences,

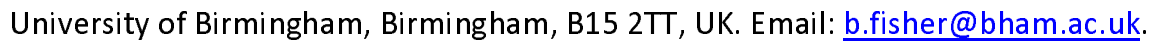

1. Department of Critical Care Medicine, University Hospitals Birmingham NHS Trust, United Kingdom

2. Birmingham Acute Care Research Group, Institute of Inflammation and Ageing, College of Medical and Dental Sciences, University of Birmingham, UK

3. Rheumatology Research Group, Institute of Inflammation and Ageing, College of Medical and Dental Sciences, University of Birmingham, UK

4. National Institute for Health Research (NIHR) Birmingham Biomedical Research Centre, University Hospitals Birmingham NHS Foundation Trust, Birmingham, UK.

5. Cancer Research UK Clinical Trials Unit, Institute of Cancer and Genomic Sciences, University of Birmingham, Birmingham, UK

6. Department of Respiratory Medicine, University Hospitals Birmingham NHS Trust, UK

7. Nuffield Department of Clinical Neurosciences, University of Oxford, John Radcliffe Hospital, Oxford, UK.

8. Department of Infectious Diseases, University Hospitals Birmingham NHS Trust, UK

9. Oxford Clinical Trials Research Unit, Botnar Research Centre, University of Oxford, Oxford, UK. 
medRxiv preprint doi: https://doi.org/10.1101/2021.02.10.21251478; this version posted February 12, 2021. The copyright holder for this preprint

(which was not certified by peer review) is the author/funder, who has granted medRxiv a license to display the preprint in perpetuity.

It is made available under a CC-BY 4.0 International license.

CATALYST

\begin{abstract}
Introduction

Severe SARS-CoV-2 infection is associated with a dysregulated immune response. Inflammatory monocytes and macrophages are crucial, promoting injurious, pro-inflammatory sequelae. Immunomodulation is, therefore, an attractive therapeutic strategy and we sought to test licensed and novel candidate drugs.
\end{abstract}

\title{
Methods and analysis
}

The CATALYST trial is a multi-arm, open-label, multi-centre, phase II platform trial designed to identify candidate novel treatments to improve outcomes of patients hospitalised with COVID-19 compared with usual care. Treatments with evidence of biomarker improvements will be put forward for larger-scale testing by current national phase III platform trials. Hospitalised patients $\geq 16$ years with a clinical picture strongly suggestive of SARS-CoV-2 pneumonia (confirmed by chest X-ray or CT scan, with or without a positive reverse transcription polymerase chain reaction (RT-PCR) assay) and a C-Reactive Protein (CRP) $\geq 40 \mathrm{mg} / \mathrm{L}$ are eligible. The primary outcome measure is CRP, measured serially from admission to day 14 , hospital discharge or death. Secondary outcomes include the WHO Clinical Progression Improvement Scale as a principal efficacy assessment.

\section{Ethics and dissemination}

The protocol was approved by the East Midlands - Nottingham 2 Research Ethics Committee (20/EM/0115) and given Urgent Public Health status; initial approval was received on 05-May-2020, current protocol version (v6.0) approval on 12-Oct-2020. The MHRA also approved all protocol versions. The results of this trial will be disseminated through national and international presentations and peerreviewed publications.

\section{Trial registration number}

EudraCT Number: 2020-001684-89

ISRCTN Number: 40580903

\section{Strengths and limitations of this trial}

- CATALYST will provide a rapid readout on the safety and proof-of-concept of candidate novel treatments

- CATALYST will enable phase III trial resources to be focussed and allocated for agents with a high likelihood of success

- CATALYST uses Bayesian multi-level models to allow for nesting of repeated measures data, with factors for each individual patient and treatment arm, and allowing for non-linear responses

- CATALYST is not designed to provide a definitive signal on clinical outcomes 


\section{Introduction}

Since the start of the pandemic, the UK has now passed the milestone of 100,000 deaths due to SARSCoV-2 virus. Current data from the International Severe Acute Respiratory and emerging Infections Consortium (ISARIC) partnerships indicate that $20 \%$ of patients admitted to the hospital require critical care support, with an overall mortality of $34.5 \%$ after hospital admission in the last two waves (1). Mortality following respiratory support remains over $40 \%$ in the second wave (2). Recovery from severe disease may be associated with long-term health impact $(3,4)$. Despite the introduction of vaccination programmes in December-2020, there remains an urgent need to identify agents which prevent progression to critical illness, reduce morality and promote rapid recovery.

SARS-CoV-2 can cause severe pneumonia with diffuse alveolar damage, infiltrating perivascular lymphocytes, disrupted endothelial cell membranes, vascular thrombosis with microangiopathy and occlusion of alveolar capillaries (5). Subsequent multiple organ failure, is in part, driven by a dysregulated immune response. Inflammatory monocytes and macrophages contribute to endothelial damage and microthrombosis and drive cytokine production. The cellular response is characterised by an upregulation of pro-inflammatory cytokines and chemokines, leading to a host immune response targeted at the virus, damaging host tissues (6). The severity of the disease is proportional to the cytokine response (interleukin (IL)-6, interferon gamma inducible protein (IP)-10, monocyte chemoattractant protein (MCP)1 , macrophage inflammatory protein (MIP)-1A, and tumour necrosis factor (TNF)- $\alpha$ ), with critically ill patients exhibiting the highest levels of cytokines and chemokines (7-9). This dysregulated immunity may be a modifiable pathobiological therapeutic target for preventing COVID-19 progression. Potential mechanisms underlying this immune pathobiology may be targeted with precision using existing licensed and novel drugs. The CATALYST platform, therefore, aims to study these drugs and other novel therapeutic options for rapid assessment of safety, biological signal for efficacy, and providing secure underpinning of science prior to large phase III trials. Those with potential efficacy can then be considered for larger-scale testing by national platform trials such as RECOVERY (10) or REMAP-CAP (11).

\section{Methods and analysis}

\section{Study design}

The CATALYST trial is a multi-arm, randomised, open-label phase II clinical trial. Initial candidate drugs included within the multi-arm design were namilumab, and infliximab, monoclonal antibodies targeting the pro-inflammatory cytokines granulocyte-macrophage colony-stimulating factor (GM-CSF) and TNF- $\alpha$ respectively. A third agent, gemtuzumab-ozogamicin (Mylotarg), was incorporated in the protocol but has not been prioritised for evaluation at this stage and has not opened to recruitment. Each candidate therapy will be given in addition to usual care and compared with usual care independently (Figure 1). Randomisation will be performed according to a 1:1 ratio (usual care versus research arms) using a minimisation procedure to stratify based on ward- or intensive care unit (ICU)-based care. New therapies may be introduced sequentially utilising this design. Therapies for evaluation will be based on the scientific rationale prioritised by a Scientific Advisory Board (SAB). This will enable the rapid addition of new treatment arms, whilst allowing the efficacious assessment and analysis of each of these treatment arms $(12,13)$. Participants are followed up for at least 28 days post-randomisation.

\section{Patient and public involvement (PPI)}

From its inception, the CATALYST trial was co-developed with the Critical Care PPI group based in the Surgical Reconstruction and Microbiology Research Centre (SRMRC) at University Hospitals Birmingham. The group reviewed and refined the protocol and participant-facing documents and provided input into

\begin{tabular}{l|l} 
UNIVERSITYOF & $@$ @IRMINGHAM
\end{tabular} vRCTU Page 3 of $15 \quad$ v0.8 10-Feb-2021


the design; specifically, their feedback supported a usual care arm without the inclusion of placebo controls given the context of the ongoing pandemic. PPI representatives are members of the Trial Steering Committee (TSC) who will supervise the conduct of the trial conduct, and monitor progress, including recruitment, and will support the dissemination of the trial results.

\section{Inclusion and exclusion criteria}

Patients aged 16 years or over, with a clinical picture strongly suggestive of SARS-CoV-2 pneumonia (confirmed by chest $\mathrm{X}$-ray or $\mathrm{CT}$ scan, with or without a positive reverse transcription-polymerase chain reaction (RT-PCR) assay), and C-Reactive Protein (CRP) greater than or equal to $40 \mathrm{mg} / \mathrm{L}$ are eligible for this study. Exclusion criteria include patient or personal/professional legal representative refusal, planned palliative care, pregnancy or breastfeeding women, women of childbearing potential and nonvasectomised men who are unwilling to use effective contraception for the duration of the trial and throughout the drug-defined post-trial period. Patients with known HIV or chronic hepatitis B or C infection, contraindications to any of the Investigational Medicinal Products, receiving concurrent immunosuppression with biological agents, a history of haematopoietic stem cell transplant or solid organ transplant, known hypersensitivity to drug products or excipients, tuberculosis or other severe infections such as (non-SARS-CoV-2) sepsis, abscesses, and opportunistic infections requiring treatment, moderate or severe heart failure (NYHA class III/IV), or any other indication or medical history, that in the opinion of the patient's local investigator is unsuitable for trial participation. Patients will not be eligible if they are currently participating in another COVID-19 interventional trial; co-enrolment into RECOVERYRespiratory Support (RS) trial is allowed.

\section{Consent}

Patients are identified as per site-established processes. This may include searching central logs of patients admitted with COVID-19, or via pre-screening processes already in situ at the site. Each eligible patient who has capacity will be given a Patient Information Sheet (PIS) to read more about the trial (Supplementary Appendix 2). Informed consent is requested from patients with capacity by an investigator who has been delegated the responsibility on the delegation log. Where a patient lacks capacity (for example from severity of illness) informed consent will be sought from the patient's personal legal representative (PerLR). In the event that the PerLR is unavailable, informed consent will be sought from the patient's professional legal representative (ProfLR) according to the requirements of the UK Health Research Authority (14). Specific PISs for both PerLR and ProfLR can also be emailed to aid this process. If a patient recovers their capacity, they should be reconsented as soon as possible using the standard PIS and Informed Consent Form (ICF). Patient and PerLR forms are also available in Bengali, English, French, Polish, Portuguese, Punjabi, Urdu, and Welsh. Supplementary Appendices 3 and 4 contain the English version of the patient, ProfLR and PerLR information sheets, and ICFs, respectively.

\section{Interventions}

Arm 1: Usual care provided following the current institutional policy for patients with COVID-19. Following the recommendation from the UK CMO in June 2020, standard care includes dexamethasone treatment.

Arm 3: Usual care combined with namilumab, administered in a single dose $(150 \mathrm{mg})$ on day one infused intravenously over 1-hour. Namilumab is an anti-GM-CSF monoclonal antibody with a good safety profile up to phase II studies in rheumatoid arthritis (RA) and axial spondyloarthropathy with over 360 individuals dosed in total (15-18). The objective of namilumab therapy in COVID-19 is to inhibit

\begin{tabular}{l|l} 
UNIVERSITYOF & $@$ BIRMINGHAM
\end{tabular} CRCTU Page 4 of $15 \quad$ v0.8 10-Feb-2021


inflammatory monocyte/macrophage activation and their trafficking to the lungs so as to reduce the aberrant immunopathology.

Arm 4: Usual care combined with infliximab, administered in a single dose of $5 \mathrm{mg} / \mathrm{Kg}$ diluted in $250 \mathrm{ml}$ of $0.9 \%$ saline on day one and infused over a 2-hour period. Infliximab is a widely available anti-TNF alpha monoclonal antibody licensed for the treatment of a number of diseases including RA. TNF is a key proinflammatory cytokine produced by macrophages implicated in a number of processes contributing to early lung pathology (19).

No dose modification for namilumab or infliximab is permitted. Although there are no requirements for pre-medication, patients may receive pre-medication or treatment with antihistamines and paracetamol at local discretion to prevent or treat mild-to-moderate infusion reactions due to namilumab or infliximab administration.

Initially, gemtuzumab-ozogamicin, an antibody-drug conjugate approved for induction therapy of acute myeloid leukaemia was included for investigation in the trial (Arm 2), however, prioritisation discussions in the Government Committee overseeing the COVID-19 phase II studies, advised that this arm should be suspended without recruitment, in favour of continuing with namilumab and infliximab arms.

\section{Trial outcomes}

The primary outcome is CRP concentration, where a sequential reduction in one of the interventional arms as compared with usual care is considered indicative that this may be a clinically effective treatment suitable for testing in phase III clinical trials.

The secondary outcomes are aligned with Core Outcome Measures in Effectiveness Trials' initiatives (20, 21). The principal clinical efficacy measure is the World Health Organisation (WHO) Clinical Progression Improvement Scale measured daily for 28 days on a 1-10 scale; level 0 (no viral load detected) will not be assessed over the course of this study (Table 1). Other clinical measures assessed until day 14, discharge, or death, include the ratio of the oxygen saturation to fractional inspired oxygen concentration $\left(\mathrm{SpO}_{2} / \mathrm{FiO}_{2}\right)$, respiratory rate, body temperature, and the National Early Warning Scale 2 (NEWS-2). Assessments assessed until day 28 include length of hospital stay, hospital survival status at day 28 , the proportion of patients discharged at day 28 , and the destination of discharge. Routine laboratory measurements at baseline, days 3, 5, 7, 9, and 14 include lymphocyte count, neutrophil count, neutrophil: lymphocyte ratio, ferritin, D-Dimer and LDH. Safety measures as defined by adverse events (AEs) and as recorded by Common Terminology Criteria for Adverse Events (CTCAE), version 4.03 (22) are those of Grade $\geq 3$, secondary infection and allergic reaction, and survival status.

In a subset of the patients (those admitted to University Hospitals Birmingham NHS Trust and University of Oxford NHS Trust) optional samples consisting of whole blood (for RNA, DNA and also cellular assessments, preserved in Cytodelics buffer), peripheral blood mononuclear cells (PBMCs), and plasma, will be obtained on days one, three and nine (or day of discharge if earlier) and will broadly follow the ISARIC protocol (23). All samples will be collected in accordance with national regulations and requirements, including standard operating procedures for logistics and infrastructure. Samples will be taken in appropriately licensed premises, stored and transported per the Human Tissue Authority guidelines and NHS trust policies.

\section{Statistical analysis plan}

The primary outcome data will consist of a sequence through time of readings of each patient's CRP. These will be modelled using Bayesian multi-level models (also known as hierarchical or mixed-effects) 
that allow for nesting of the repeated measures data within patient, and allowing for non-linear responses. Specifically, posterior probabilities for the treatment/time interaction covariates will be used to conduct decision making. Data will be analysed for each intervention arm against the control group, including in each analysis, only participants who were eligible for that comparison. Any important covariates will be incorporated accordingly into the model structure e.g., age and care status.

At the specified decision points, with interim analysis at $n=20$ and $n=40$ and a final analysis at $n=60$ per arm, CRP data will be considered in the context of the emerging safety data to make a recommendation as outlined below:

a) If there is strong evidence of an additional inflammatory effect (CRP) and a satisfactory safety profile consider progression to clinical endpoint evaluation whether in this trial or in another one;

b) Terminate arm and do not proceed (based on lack of evidence of an additional biological effect or of an unfavourable safety signal).

Success will be declared if there is a $90 \%$ probability that the intervention arm is better than usual care in reducing CRP. Futility is defined as less than $50 \%$ probability of the intervention being better than usual care. However, given the large number of agents being investigated in various phase II trials, the size of effect and the totality of data will be reviewed before recommending adoption by a phase III platform. In the event of a successful treatment being identified and the effect size being large, consideration may be given to continuing the arm within CATALYST to study clinical efficacy (based on the WHO scale), if this were deemed to be a more efficient path than translation to a phase III platform. More information, including the operating characteristics based on a simpler analysis of the area under the curve for sequential CRP data are included in Supplemental Appendix 4.

New arms will be added as new interventions become available. All comparisons will be performed temporally with regards to the control arm data as new arms are added A detailed secondary outcome measure analysis can be found in the Statistical Analysis Plan. Exploratory subgroup analyses will be conducted to ascertain the effect of treatment on the primary outcome measure within care status strata. Analyses will be conducted as per the primary outcome measure with any inference based on the treatment/time interaction covariate included in the model formulation.

\section{Adverse events reporting and analysis}

The collection and reporting of AEs will be in accordance with the Research Governance Framework for Health and Social Care and the requirements of the National Research Ethics Service (NRES). Definitions of different types of AEs are listed in Supplementary Appendix 5. The reporting period for AEs will be between the date of commencement of protocol-defined treatment until day 28 . The investigator should assess the seriousness and causality (relatedness) of all AEs experienced by the patient (this should be documented in the source data) with reference to the protocol. Abnormal laboratory findings will only be reported if they satisfy one of the following; (a) events which are Grade 3 or above; (b) events which result in the early discontinuation of trial treatment (if applicable to the research arm); or (c) events which result in a dose modification or dose interruption (if applicable to the research arm). Pre-existing conditions and pre-existing abnormal laboratory findings will only be reported if the condition worsens by at least one CTCAE grade. Hospitalisations for pre-planned elective procedures, unless the condition worsens, will not be reported as Serious (S)AEs. 


\section{Data management}

Data will be collected via a set of forms capturing details of eligibility, baseline characteristics, treatment and outcome details created using FORMAP Case Report Form design software developed by Birmingham Clinical Trials Unit at the University of Birmingham. This trial will use an electronic remote data capture system, with the exception of SAE reporting and notification of pregnancy; these are both paper-based. All trial records must be archived and securely retained for at least 25 years. No documents will be destroyed without prior approval from the sponsor, via the central CATALYST Trial Office. On-site monitoring will be carried out as required following a risk assessment and as documented in the Quality Management Plan. Any monitoring activities will be reported to the central CATALYST Trial Office and any issues noted will be followed up to resolution. CATALYST will also be centrally monitored, which may trigger additional on-site monitoring. Further information regarding data management is provided in the study protocol.

\section{Trial organisation structure}

The University of Birmingham will act as single sponsor for this multi-centre study. The trial is being conducted under the auspices of the Cancer Research UK Clinical Trials Unit (CRCTU), University of Birmingham, in close partnership with the National Institute for Health Research (NIHR) Biomedical Research Centres (BRC) at the Universities of Birmingham and Oxford, University College London (UCL) and Imperial College London.

Given the combination of a novel disease, a range of novel potential therapies and a pandemic setting, a multidisciplinary collaboration was essential, bringing together experts in acute, respiratory and intensive care medicine, inflammation, oncology, data sciences, trials methodology and statistics. The Birmingham Acute Care Research group provides a single point of reference for the acute specialities (24).

The trial management group (TMG) is responsible for the day-to-day running and management of the trial. Members include the Chief Investigator, Deputy Chief Investigator, Co-investigators, Trial Statisticians, Trial Management Team Leader and Trial Coordinator. The TMG reports to the TSC.

The TSC provides oversight and governance. Members include independent clinicians and patient advocates. The TSC supervises the conduct of the trial, monitoring progress including recruitment, data completeness, losses to follow-up, and deviations from the protocol. They will make recommendations about conduct and continuation of the trial.

The independent data monitoring committee (DMC) includes clinicians and a statistician who will review unblinded data analyses to advise the TSC on whether the trial data (and results from other relevant research), justifies the continuing recruitment of further patients. The DMC will operate in accordance with a trial-specific charter based on the template created by the Damocles Group. The DMC will review the trial data three-monthly during the recruitment and while patients remain on treatment. These may occur more frequently if the DMC deem necessary or for interventions which have not previously been administered to patients in this specific setting.

The SAB makes recommendations on prioritising interventions and aspects of methodology such as coenrolment in order to harmonise trial activities with other research platforms. The SAB includes multistakeholder representatives (detailed in Supplementary Appendix 1) including, the collaborating centres and the associated Biomedical Research Centres (25) in Birmingham (26), Oxford (27), and University College London (28). 
CATALYST

\section{Confidentiality statement}

Confidential trial data will be stored in accordance with the General Data Protection Regulation (GDPR) 2018. As specified in the patient information sheet and with the patient's consent, patients will be identified using only their date of birth and unique trial ID number.

\section{Trial status}

Recruitment for the trial opened in May 2020 with the namilumab and infliximab arms. Although included in the protocol, the gemtuzumab-ozogamicin arm has not opened to recruitment.

\section{Discussion}

CATALYST is a nimble, accelerated, open-label, targeted phase II proof-of-principle multi-arm trial permitting efficient evaluation of repurposed and/or novel drugs to modify the disease progression of COVID-19 in patients admitted to wards and ICU. CATALYST aims to determine suitability of a proposed new treatment for evaluation in phase III national platform trials. CATALYST has an adaptive platform design, aiming to translate laboratory-based research to patients with SARS-CoV-2 infection without delay.

This trial is designed with clinical pressures caused by the pandemic in mind. Outcomes are easy to record, location-independent, and applicable across the spectrum of illness severity. We have also prioritised serial continuous measures over discontinuous or ordinal metrics, as these allow for greater statistical efficiency and thus smaller sample sizes. The primary outcome chosen provides a rapid, biologically-driven efficacy signal to allow early "go/no-go" decisions. While the WHO has adopted a consensus-based set of core outcome measures for studies of SARS-CoV-2 infection (29), our study aim was to develop a trial with a smaller sample size to provide earlier signals of potential efficacy for multiple investigational agents, allowing selection of the most promising to be taken forward by larger platforms with clinical outcomes.

We initially considered $\mathrm{SpO}_{2} / \mathrm{FiO}_{2}$ as a suitable primary outcome for CATALYST. This is an indicator of the severity, progression, or remission of acute lung injury (30). However, as real-world data emerged, we found the relationship between the ratio and outcome was complex and was also susceptible to measurement error in patients receiving ward-based forms of respiratory support. Furthermore, its prognostic utility is compromised if the inspired oxygen concentration is not rapidly adjusted to the patients' needs by the attending staff, which is often delayed in a pandemic. Other shortfalls included high variability between observations, the impact on the measure of switching the mode of oxygen delivery, and microthrombotic events altering $\mathrm{SpO}_{2} / \mathrm{FiO}_{2}$ through alteration of perfusion (31). We, therefore, evaluated whether CRP would be a better primary outcome.

C-Reactive Protein is produced as a homopentameric protein, termed native CRP (nCRP), which can irreversibly dissociate at sites of inflammation, tissue damage, and infection into five separate monomers, termed monomeric CRP (mCRP) (32). C-Reactive Protein levels are widely used as a marker of infection or inflammation; however, evidence suggests that CRP plays an active role in the inflammatory process (33-38).

During the first wave we modelled data on CRP over time in COVID-19 patients finding that it performed better than $\mathrm{SpO}_{2} / \mathrm{FiO}_{2}$. This is consistent with published data indicating that baseline and peak CRP, median CRP over time, slope of CRP rise over seven days, and rapid rise during early disease are all associated with outcome in hospitalised patients with COVID-19 (39-42). CRP trends over time tend to have greater predictive power, with change in CRP levels performing better at predicting respiratory

\section{\begin{tabular}{l|l} 
UNIVERSITYOF & $@$ CRCTU Page 8 of 15
\end{tabular}}

v0.8 10-Feb-2021 
failure and subsequent intubation than baseline CRP or respiratory rate-oxygenation (ROX) index (40). In addition, compared to those that die, patients who survive have lower peak CRP levels and earlier reductions (41). Notably, CRP at baseline also correlates with CT grading of lung involvement (43).

The recent success of dexamethasone in the treatment of COVID-19 reinforces the relevance of inflammatory pathology to clinical outcomes (44). Methylprednisolone has been associated with CRP reduction over seven days and improved clinical outcomes, in a strategy that continued this steroid until a target CRP, or the ratio of arterial oxygen partial pressure to fractional inspired oxygen $\left(\mathrm{PiO}_{2} / \mathrm{FiO}_{2}\right)$ threshold, was reached (45). Although IL-6 blockade has a direct effect on CRP production, which might obscure a relationship between CRP trends and outcome, small studies have suggested a differential effect on CRP decline between clinical responders and non-responders $(46,47)$.

While CRP may not show complete concordance with clinical outcomes, we argue that if dysregulated inflammation is indeed a key pathogenic driver in severe COVID-19, an immunomodulating drug capable of ameliorating those outcomes is also likely to show early improvement of CRP. Conversely, an immunomodulating drug unable to influence CRP is a less promising candidate to investigate in large phase III trials. Limitations of CRP, however, include lower utility for candidate therapeutics whose mechanism of action is not immunomodulation, and the diminished ability to assess drugs that directly target IL-6, due to the direct pharmacodynamics effects on CRP. This study was designed before use of IL6 blockade outside of trials, and if tocilizumab were to be widely adopted, adaptive modification of the current trial design may be required to account for this.

In conclusion, the major strength of CATALYST is its ability to provide a rapid readout on safety, and proof-of-efficacy enabling phase III trial resources to be focussed and allocated for drugs with a high likelihood of success $(44,48)$. This will reduce the time lag in translating early phase drugs into effective therapeutics for COVID-19.

\section{Ethics and dissemination}

The trial will be performed in accordance with the recommendations guiding physicians in biomedical research involving human subjects, adopted by the $18^{\text {th }}$ World Medical Association General Assembly, Helsinki, Finland and stated in the respective participating countries laws governing human research, and Good Clinical Practice. The initial protocol was approved by East Midlands - Nottingham 2 Research Ethics Committee, (REC Ref: 20/EM/0115) on 05-May-2020, with subsequent amendments approved on 28May-2020 (addition of namilumab and infliximab), 12-Jun-2020 (inclusion change - suspected COVID-19), 20-Jun-2020 (following dexamethasone as standard of care use), 12-Oct-2020 (change of primary outcome to (RP). The MHRA has given its approval of all protocol versions; current version in use is 6.0.

A meeting will be held after the end of the trial to allow discussion of the main results among the collaborators prior to publication. Results of the primary and secondary endpoints will be submitted for publication in peer-reviewed journals.

\section{Contributors}

Study conception: TV, BAF, DS, AR, RS, DT, TW, MR, DP, DR, JB, PK, SG. Study design: TV, BAF, DS, AR, RS, DT, TW, MR, JS, DP, SJB, JSS, DR, JB, PK, SG. DS is the Trial Biostatistician and SG is the Senior Trial Biostatistician, both were responsible for developing the statistical plan. 
medRxiv preprint doi: https://doi.org/10.1101/2021.02.10.21251478; this version posted February 12, 2021. The copyright holder for this preprint (which was not certified by peer review) is the author/funder, who has granted medRxiv a license to display the preprint in perpetuity.

It is made available under a CC-BY 4.0 International license.

CATALYST

\section{Funding}

This trial is supported by the Medical Research Council (MRC) grant number MC_PC_20007. SG is supported by a Senior Investigator Award from the National Institute of Health Research. Staff at the CRCTU are supported by core funding grants from Cancer Research UK (C22436/A25354), the NIHR Biomedical Research Centre (BRC-1215-20009), The Kennedy Trust for Rheumatology Research as part of the Arthritis - Trials Acceleration Programme (KENN161704), and Innovate UK as part of the Midlands Wales Advanced Therapy Treatment Centres (104232). This paper presents independent research supported by the NIHR Birmingham Biomedical Research Centres at the University Hospitals Birmingham NHS Foundation Trust and the University of Birmingham, as well as Oxford and University College London Hospitals Biomedical Research Centres. The views expressed are those of the authors and not necessarily those of the NHS, the NIHR or the Department of Health and Social Care. Namilumab is being provided free of charge by Izana Bioscience, Oxford, UK (now part of Roivant). Infliximab is being provided free of charge by Celltrion.

\section{Competing interests}

BAF has undertaken consultancy for Novartis, BMS, Servier, Galapagos and Janssen; MR is currently undertaking a Senior Clinical Fellowship financed by Roche; PK has undertaken consultancy for BMS, AstraZeneca, and AbbVie; all are unrelated to this trial. All other authors declare no competing interests.

\section{Acknowledgements}

We thank staff from the CRCTU, University of Birmingham including Dr Siân Lax for contributions to the paper.

\section{References}

1. Hall M, Pritchard M, Dankwa EA, Baillie JK, Carson G, Cita rella BW, et al. ISARIC Clinical Data Report 20 November 2020. medRxiv. 2020:2020.07.17.20155218.

2. ICNARC Report on COVID-19 in Critcal Care: England, Wales and Northern Ireland, 29 January 2021 [Available from: https://www.icnarc.org/Our-Audit/Audits/Cmp/Reports.

3. Huang C, Huang L, Wang Y, Li X, Ren L, Gu X, et al. 6-month Consequences of COVID-19 in Patients Discharged from Hospital: A Cohort Study. The Lancet. 2021;397(10270):220-32.

4. Raman B, Cassar MP, Tunnicliffe EM, Filippini N, Griffanti L, Alfaro-Almagro F, et al. Medium-term Effects of SARS-CoV-2 Infection on Multiple Vital Organs, Exercise Capacity, Cognition, Quality of Life and Mental Health, Post-hospital Discharge. EClinicalMedicine. 2021;31:100683.

5. Ackermann M, Verleden SE, Kuehnel M, Haverich A, Welte T, Laenger F, et al. Pulmonary Vascular Endothelialitis, Thrombosis, and Angiogenes is in Covid-19. New England Journal of Medicine. 2020;383(2):1208.

6. Leisman DE, Ronner L, Pinotti R, Taylor MD, Sinha P, Calfee CS, et al. Cytokine Elevation in Severe and Critical COVID-19: A Rapid Systematic Review, Meta-analysis, and Comparison with other Inflammatory Syndromes. The Lancet Respiratory Medicine. 2020;8(12):1233-44.

7. Huang C, Wang Y, Li X, Ren L, Zhao J, Hu Y, et al. Clinical Features of Patients Infected with 2019 Novel Coronavirus in Wuhan, China. The Lancet. 2020;395(10223):497-506.

8. Liao M, Liu Y, Yuan J, Wen Y, Xu G, Zhao J, et al. Single-cell Landscape of Bronchoalveolar Immune Cells in Patients with COVID-19. Nature Medicine. 2020;26(6):842-4. 
medRxiv preprint doi: https://doi.org/10.1101/2021.02.10.21251478; this version posted February 12, 2021. The copyright holder for this preprint (which was not certified by peer review) is the author/funder, who has granted medRxiv a license to display the preprint in perpetuity.

It is made available under a CC-BY 4.0 International license.

CATALYST

9. Prompetchara E, Ketloy C, Palaga T. Immune Responses in COVID-19 and Potential Vaccines: Lessons Learned from SARS and MERS Epidemic. Asian Pacific Journal of Allergy and Immunology. 2020;38:1-9.

10. Randomised Evaluation of COVID-19 Therapy (RECOVERY) Trial Protocol 2020 [Available from: https://www.recoverytrial.net/for-site-staff.

11. Randomized, Embedded, Multifactorial Adaptive Platform trial for CommunityAcquired Pneumonia (REMAP-CAP): Core Protocol 2020 [Available from: https://www.remapcap.org/protocol-documents.

12. Dean NE, Gsell P-S, Brookmeyer R, Crawford FW, Donnelly CA, Ellenberg SS, et al. Creating a Framework for Conducting Randomized Clinical Trials during Disease Outbreaks. New England Journal of Medicine. 2020;382(14):1366-9.

13. Kieny MP, Salama P. WHO R\&D Blueprint: a global coordination mechanism for R\&D preparedness. Lancet. 2017;389(10088):2469-70.

14. Health Research Authority Consent and Participant Information Guidance [Available from: http://www.hra-decisiontools.org.uk/consent/principles-ALC-EnglandandWales.html.

15. Papp KA, Gooderham M, Jenkins R, Vender R, Szepietowski JC, Wagner T, et al. Granulocytemacrophage Colony-stimulating Factor (GM-CSF) as a Therapeutic Target in Psoriasis: Randomized, Controlled Investigation using Namilumab, a Specific Human anti-GM-CSF Monoclonal Antibody. British Journal of Dermatology. 2019;180(6):1352-60.

16. Tanaka S, Harada S, Hiramatsu N, Nakaya R, Kawamura M. Randomized, double-blind, placebocontrolled, phase I study of the safety and pharmacokinetics of namilumab in healthy Japanese and Caucasian men $\square$ International Journal of Clinical Pharmacology and Therapeutics. 2018;56(11):507-17.

17. Huizinga TW, Batalov A, Stoilov R, Lloyd E, Wagner T, Saurigny D, et al. Phase 1b Randomized, Doubleblind Study of Namilumab, an anti-Granulocyte Macrophage Colony-stimulating Factor Monoclonal Antibody, in Mild-to-moderate Rheumatoid Arthritis. Arthritis Research \& Therapy. 2017;19(1):53.

18. Taylor PC, Saurigny D, Vencovsky J, Takeuchi T, Nakamura T, Matsievskaia G, et al. Efficacy and Safety of Namilumab, a Human Monoclonal Antibody Against Granulocyte-macrophage Colony-stimulating Factor (GM-CSF) Ligand in Patients with Rheumatoid Arthritis (RA) with Either an Inadequate Response to Background Methotrexate Therapy or an Inadequate Response or Intolerance to an anti-TNF (Tumour Necrosis Factor) Biologic Therapy: A Randomized, Controlled Trial. Arthritis Research \& Therapy. 2019;21(1):101.

19. Robinson PC, Richards D, Tanner HL, Feldmann M. Accumulating Evidence Suggests anti-TNF Therapy Needs to be Given Trial Priority in COVID-19 Treatment. The Lancet Rheumatology. 2020;2(11):e653e5.

20. Williamson PR, Altman DG, Bagley H, Barnes KL, Blazeby JM, Brookes ST, et al. The COMET Handbook: version 1.0. Trials. 2017;18(3):280.

21. Core Outcome Measures in Effectiveness Trials [Available from: http://www.comet-initiative.org/.

22. Cancer Therapy Evaluation Program. Common Terminology Criteria for Adverse Events (CTCAE), Version 4.03. US Department of Health and Human Services, NIH, NCI. 2010.

23. ISARIC/WHO Clinical Characterisation Protocol for Severe Emerging Infections 2020 [Available from: https://isaric.tghn.org/clinical-characterisation-protocol-ccp/.

24. University of Birmingham Acute Care Research [Available from: https://www.birmingham.ac.uk/research/inflammation-ageing/acute-care-research.aspx.

25. National Institute for Health Research Biomedical Research Centres [Available from: https://www.nihr.ac.uk/explore-nihr/support/experimental-medicine.htm.

26. National Institute for Health Research Birmingham Biomedical Research Centre [Available from: https://www.birminghambrc.nihr.ac.uk/.

27. National Institute for Health Research Oxford Health Biomedical Research Centre [Available from: https://oxfordhealthbrc.nihr.ac.uk/.

28. National Institute for Health Research University College London Hospitals Biomedical Research Centre [Available from: https://www.uclhospitals.brc.nihr.ac.uk/content/biomedical-research-centre. 
medRxiv preprint doi: https://doi.org/10.1101/2021.02.10.21251478; this version posted February 12, 2021. The copyright holder for this preprint (which was not certified by peer review) is the author/funder, who has granted medRxiv a license to display the preprint in perpetuity.

It is made available under a CC-BY 4.0 International license.

CATALYST

29. Marshall JC, Murthy S, Diaz J, Adhikari NK, Angus DC, Arabi YM, et al. A Minimal Common Outcome Measure Set for COVID-19 Clinical Research. The Lancet Infectious Diseases. 2020;20(8):e192-e7.

30. The ARDS Definition Task Force. Acute Respiratory Distress Syndrome: The Berlin Definition. JAMA. 2012;307(23):2526-33.

31. Vlaar APJ, de Bruin S, Busch M, Timmermans S, van Zeggeren IE, Koning R, et al. Anti-C5a Antibody IFX-1 (Vilobelimab) Treatment versus Best Supportive Care for Patients with Severe COVID-19 (PANAMO): An Exploratory, Open-label, Phase 2 Randomised Controlled Trial. The Lancet Rheumatology. 2020;2(12):e764e73.

32. Sproston NR, Ashworth JJ. Role of C-Reactive Protein at Sites of Inflammation and Infection. Front Immunol. 2018;9:754-.

33. Thiele JR, Habersberger J, Braig D, Schmidt Y, Goerendt K, Maurer V, et al. Dissociation of Pentameric to Monomeric C-reactive Protein Localizes and Aggravates Inflammation: In Vivo Proof of a Powerful Proinflammatory Mechanism and a New Anti-inflammatory Strategy. Circulation. 2014;130(1):35-50.

34. Khreiss T, József L, Hossain S, Chan JS, Potempa LA, Filep JG. Loss of Pentameric Symmetry of Creactive Protein is Associated with Delayed Apoptosis of Human Neutrophils. Journal of Biological Chemistry. 2002;277(43):40775-81.

35. Singh U, Devaraj S, Vasquez-Vivar J, Jialal I. C-reactive Protein Decreases Endothelial Nitric Oxide Synthase Activity via Uncoupling. Journal of Molecular and Cellular Cardiology. 2007;43(6):780-91.

36. Krayem I, Bazzi S, Karam M. The Combination of CRP Isoforms with oxLDL Decreases TNF- $\alpha$ and IL-6 Release by U937-derived Macrophages. Biomed Rep. 2017;7(3):272-6.

37. Khreiss T, József L, Potempa LA, Filep JG. Loss of Pentameric Symmetry in C-reactive Protein Induces Interleukin-8 Secretion Through Peroxynitrite Signaling in Human Neutrophils. Circulation Research. 2005;97(7):690-7.

38. Han KH, Hong KH, Park JH, Ko J, Kang DH, Choi KJ, et al. C-reactive Protein Promotes Monocyte Chemoattractant Protein-1 - Mediated Chemotaxis through Upregulating CC Chemokine Receptor 2 Expression in Human Monocytes. Circulation. 2004;109(21):2566-71.

39. Luo X, Zhou W, Yan X, Guo T, Wang B, Xia H, et al. Prognostic Value of C-Reactive Protein in Patients With Coronavirus 2019. Clinical Infectious Diseases. 2020;71(16):2174-9.

40. Mueller AA, Tamura T, Crowley CP, DeGrado JR, Haider H, Jezmir JL, et al. Inflammatory Biomarker Trends Predict Respiratory Decline in COVID-19 Patients. Cell Reports Medicine. 2020;1(8):100144.

41. Sharifpour M, Rangaraju S, Liu M, Alabyad D, Nahab FB, Creel-Bulos CM, et al. C-reactive Protein as a Prognostic Indicator in Hospitalized Patients with COVID-19. PLoS One. 2020;15(11):e0242400.

42. Malik P, Patel U, Mehta D, Patel N, Kelkar R, Akrmah M, et al. Biomarkers and Outcomes of COVID-19 Hospitalisations: Systematic Review and Meta-analysis. BMJ Evidence Based Medicine. 2020:doi: 10.1136/bmjebm-2020-111536.

43. Tan C, Huang Y, Shi F, Tan K, Ma Q, Chen Y, et al. C-reactive Protein Correlates with Computed Tomographic Findings and Predicts Severe COVID-19 Early. Journal of Medical Virology. 2020;92(7):856-62.

44. Horby P, Lim WS, Emberson JR, Mafham M, Bell JL, Linsell L, et al. Dexamethasone in Hospitalized Patients with Covid-19 - Preliminary Report. New England Journal of Medicine. 2020:doi: 10.1056/NEJMoa2021436.

45. Salton F, Confalonieri P, Meduri GU, Santus P, Harari S, Scala R, et al. Prolonged Low-Dose Methylprednisolone in Patients With Severe COVID-19 Pneumonia. Open Forum Infectious Diseases. 2020;7(10):ofaa421.

46. Montesarchio V, Parrela R, lommelli C, Bianco A, Manzillo E, Fraganza F, et al. Outcomes and Biomarker Analyses Among Patients with COVID-19 Treated with Interleukin 6 (IL-6) Receptor Antagonist Sa rilumab at a Single Institution in Italy. Journal for Immunotherapy of Cancer. 2020;8(2):e001089.

47. Jordan SC, Zakowski P, Tran HP, Smith EA, Gaultier C, Marks G, et al. Compassionate Use of Tocilizumab for Treatment of SARS-CoV-2 Pneumonia. Clinical Infectious Diseases. 2020;71(12):3168-73.

\section{\begin{tabular}{l|l} 
UNIVERSITYF & $@$ BIRMINGHAM
\end{tabular} CRCTU Page 12 of 15}


medRxiv preprint doi: https://doi.org/10.1101/2021.02.10.21251478; this version posted February 12, 2021. The copyright holder for this preprint (which was not certified by peer review) is the author/funder, who has granted medRxiv a license to display the preprint in perpetuity.

It is made available under a CC-BY 4.0 International license.

CATALYST

48. RECOVERY Collaborative Group. Azithromycin in Patients Admitted to Hospital with COVID-19 (RECOVERY): A Randomised, Controlled, Open-label, Platform Trial. The Lancet. 2021:doi: 10.1016/s01406736(21)00149-5. 
medRxiv preprint doi: https://doi.org/10.1101/2021.02.10.21251478; this version posted February 12, 2021. The copyright holder for this preprint (which was not certified by peer review) is the author/funder, who has granted medRxiv a license to display the preprint in perpetuity.

\section{It is made available under a CC-BY 4.0 International license .}

CATALYST

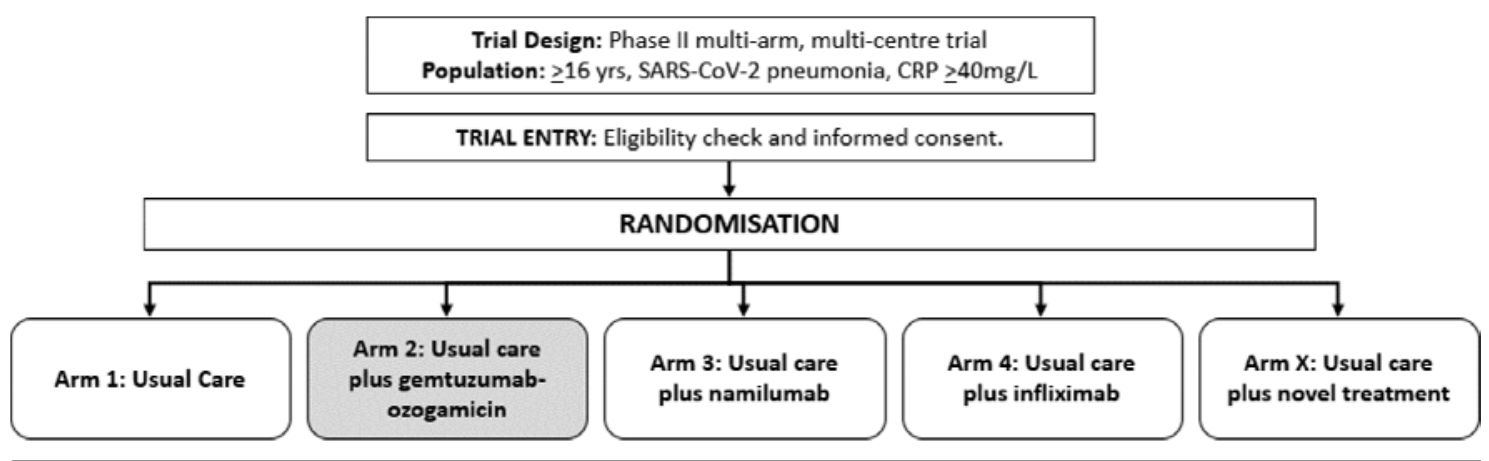

Daily on-trial assessments: $\mathrm{WHO}$ clinical progression scale, NEWS-2, $\mathrm{FiO}_{2}$ levels, $\mathrm{O}_{2}$ saturations, body temperature and pulse rate

PRIMARY OUTCOME: Serial CRP levels

Key Secondary Outcomes:

i. Efficacy: Improvement in WHO clinical progression scale measured from randomisation to days 7, 14 and 28

ii. Clinical outcomes:

Respiratory rate, body temperature, length of hospital stay, hospital survival status at day 28 , proportion of patients discharged at day 28 , destination of discharge

iii. Safety: Grade $\geq 3$ AEs with interest in veno-occlusive disease, secondary infection and allergic reaction, and survival status

\section{Figure 1 CATALYST Trial Schema}

The gemtuzumab-ozogamicin arm has been de-prioritised and is not open to recruitment.

$\mathrm{AE}$, adverse events; CRP, C-reactive protein; NEW-2, National Early Warning Scale 2; WHO, World Health Organisation 
CATALYST

\section{Table 1 World Health Organisation Clinical Progression Scale}

\begin{tabular}{|c|c|c|}
\hline Patient State & Descriptor & Score \\
\hline Uninfected & Uninfected; no viral RNA detected & 0 \\
\hline \multirow[t]{3}{*}{ Ambulatory } & Asymptomatic; viral RNA detected & 1 \\
\hline & Symptomatic; independent & 2 \\
\hline & Symptomatic; assistance needed & 3 \\
\hline \multirow{2}{*}{ Hospitalised; mild disease } & Hospitalised; no oxygen therapy & 4 \\
\hline & Hospitalised; oxygen by mask or nasal prongs & 5 \\
\hline \multirow{4}{*}{ Hospitalised; severe disease } & Hospitalised; oxygen by NIV or high flow & 6 \\
\hline & $\begin{array}{l}\text { Intubated and mechanical ventilation, } \\
\mathrm{pO}_{2} / \mathrm{FiO}_{2} \geq 150 \text { or } \mathrm{SpO}_{2} / \mathrm{FiO}_{2} \geq 200\end{array}$ & 7 \\
\hline & $\begin{array}{l}\text { Mechanical ventilation } \\
\mathrm{pO}_{2} / \mathrm{FiO}_{2}<150\left(\mathrm{SpO}_{2} / \mathrm{FiO}_{2}<200\right) \text { or vasopressors }\end{array}$ & 8 \\
\hline & $\begin{array}{l}\text { Mechanical ventilation } \\
\mathrm{pO}_{2} / \mathrm{FiO}_{2}<150\left(\mathrm{SpO}_{2} / \mathrm{FiO}_{2}<200\right) \text { and vasopressors, dialysis } \\
\text { or ECMO }\end{array}$ & 9 \\
\hline Death & Dead & 10 \\
\hline
\end{tabular}

Adapted from Marshall et al., 2020 (29).

\section{Footnotes for use in CATALYST}

1. If $\mathrm{pO}_{2}$ not available then use the $\mathrm{SpO}_{2} / \mathrm{FiO}_{2}$ ratio instead

2. For $\mathrm{pO}_{2}$ measurements in $\mathrm{kPa}$, use an online calculator e.g. https://www.msdmanuals.com/en$\mathrm{gb} /$ medical-calculators $/ \mathrm{PaO}_{2}-\mathrm{FiO}_{2}$ Ratio.htm to calculate a $\mathrm{pO}_{2} / \mathrm{FiO}_{2}$ ratio equivalent to that obtained with $\mathrm{pO}_{2}$ measured in $\mathrm{mmHg}$, or else consider an equivalent ratio to 200 , when dividing $\mathrm{pO}_{2}$ in $\mathrm{kPa}$ by $\mathrm{FiO}_{2}$, is 26.7, and an equivalent to 150 is 20 .

3. If medically fit for discharge, record status as for ambulatory patient

4. Asymptomatic implies a return to baseline symptomatic state, i.e. no fever, and no cough, shortness of breath, confusion, myalgia, diarrhoea, fatigue, or weakness above what the participant would have experienced on a daily basis before their COVID-19 episode

5. Symptomatic but independent, implies that the participant has some of the additional symptoms as above, but needs no additional help with activities of daily living above what they required prior to their COVID-19 episode.

6. Symptomatic but needs assistance, implies that in addition to having symptoms as above, they require help with activities of daily living i.e. bathing/showering, personal hygiene and combing of hair, dressing, toileting, mobility/transferring and self-feeding, above what they required on a daily basis prior to their COVID-19 episode.

7. Score 0 (uninfected: no viral RNA detected) is not being assessed as part of CATALYST. 